\title{
O ENSINO DO ESPORTE ATRAVÉS DO JOGO: ANÁLISE, POSSIBI- LIDADES E DESAFIOS NA EDUCAÇÃO FÍSICA ESCOLAR
}

\author{
João Gilberto Mattos Giusti \\ Faculdades Anhanguera Educacional de Pelotas, Pelotas, Rio Grande do Sul, Brasil \\ Larissa Rafaela Galatti \\ Universidade Estadual de Campinas, Campinas, São Paulo, Brasil \\ Rogério da Cunha Voser \\ Universidade Federal do Rio Grande do Sul, Porto Alegre, Rio Grande do Sul, Brasil \\ Mario Renato Azevedo \\ Universidade Federal de Pelotas, Pelotas, Rio Grande do Sul, Brasil
}

\begin{abstract}
Resumo
O objetivo do estudo foi analisar a utilização do jogo como ferramenta metodológica para o ensino do esporte na Educação Física escolar. Professores vinculados às redes municipal e estadual atuantes na cidade de Pelotas $(\mathrm{RS})(\mathrm{N}=54)$ responderam um questionário que abordou a metodologia preferencial para o ensino das modalidades esportivas coletivas. A partir destes, foram identificados seis docentes cuja intervenção tinha características de ensino do esporte pautado pelo jogo. Estes foram selecionados, sendo suas aulas de Educação Física observadas e analisadas. Os resultados mostraram a factibilidade da utilização de diferentes estruturas de jogo na iniciação às modalidades coletivas envolvidas no ambiente escolar, apesar das limitações estruturais identificadas, como espaço físico e disponibilidade de materiais.
\end{abstract} Palavras-chave: Educação Física. Esporte. Metodologia.

\section{Introdução}

O esporte como conteúdo nas aulas de Educação Física ainda ocupa espaço importante e quase hegemônico na escola (FORTES et al., 2012), fazendo com que muitas vezes se confunda com a própria Educação Física (BETTI, 1999; DARIDO, 2008).

As modalidades esportivas, ao serem consideradas como conteúdos na escola, devem ser abordadas a partir de suas dimensões procedimental, conceitual e atitudinal (DARIDO, 2008). Em relação aos aspectos procedimentais, a tática e a técnica nos jogos esportivos coletivos representam conteúdos fundamentais a serem desenvolvidos (GRECO; SILVA; SANTOS, 2009); é nesses aspectos que se centra este estudo.

O debate sobre as metodologias de ensino dos esportes coletivos se intensificou a partir da década de 1990 (GRAÇA; OLIVEIRA, 1995; GRECO; BENDA, 1998; GARGANTA, 1998), apontando para a necessidade de reformulações conceituais e procedimentais no seu trato pedagógico (REVERDITO; SCAGLIA, 2009). Assim, no que se refere à metodologia, 
há mais de duas décadas se defende a superação do modelo tecnicista, quando se enfatiza o trabalho das partes em detrimento do todo (jogo) (GARGANTA, 1995; GRECO; BENDA, 1998; REVERDITO; SCAGLIA, 2009; GALATTI et al., 2014).

Uma metodologia de ensino do esporte pautada no princípio analítico-sintético (DIETRICH; DÜRRWÄCHTER; SCHALLER, 1984) se caracteriza pela utilização de exercícios que promovem o conhecimento, a aprendizagem e/ou o aperfeiçoamento de elementos técnicos das modalidades esportivas. Outro aspecto que caracteriza tal abordagem é o fato de que a execução das tarefas se dá fora do ambiente de jogo, quando não há enfrentamento entre adversários ou apelo para a tomada de decisão. Do ponto de vista da transferência dessa aprendizagem para o jogo (principal objetivo), a ausência da "situação de jogo" resulta em sua maior limitação (GARGANTA, 1995; GRECO; BENDA, 1998).

Reverdito e Scaglia (2009), ao revisarem os estudos de importantes autores da área a respeito do ensino dos jogos coletivos de invasão, mostraram que atualmente há praticamente uma unanimidade na literatura quanto à importância do jogo no processo de ensino das modalidades esportivas coletivas. O jogo, além de imprevisível, possibilita o desafio, a motivação e a participação, apresentando constantes problemas que exigem respostas criativas e hábeis, individuais e coletivas e permitindo ao aluno compreender a sua complexidade, de forma autônoma, inclusiva e diversificada (PAES, 2009). Nesse sentido, as estratégias metodológicas devem ser orientadas por um processo de ensino para a compreensão do jogo em que somente jogando-o é possível potencializar a capacidade do sujeito de jogar melhor (REVERDITO E SCAGLIA, 2009).

Diversos autores vêm propondo, de forma objetiva, estratégias que possam viabilizar o ensino do esporte através do jogo (BUNKER; THORPE, 1982; BAYER, 1994; GRIFFIN et al, 1997; GARGANTA, 1998; GRECO; BENDA, 1998; SIEDENTOP, 2002; SCAGLIA; REVERDITO; GALATTI, 2013), indicando possibilidades de prática que fomentam um ambiente de aprendizagem que contemple técnica e tática simultaneamente, em modelos agrupados por Côté et al. (2007) como "play practice" ou "prática do jogo".

Se, por um lado, há evolução teórica evidente na área da pedagogia do esporte, por outro, na prática, estudos sugerem que o modelo tradicional ainda persiste no contexto da iniciação esportiva, ou seja, com demasiada ênfase aos procedimentos de ensino pautados no princípio analítico-sintético (GRECO, 1998; COUTINHO; SILVA, 2009; GALATTI et al., 2013). A influência da experiência esportiva do professor (ex-atleta) vem sendo apontada como um dos aspectos determinantes das práticas pedagógicas de professores e treinadores (RAMOS; GRAÇA; NASCIMENTO, 2006) e que podem ajudar a explicar o cenário atual.

Além disso, o contexto da aula de Educação Física escolar normalmente se apresenta como desafiador para que o professor planeje e ensine o esporte. Algumas limitações são frequentemente citadas, como a restrição de espaço e material (WITTIZORECKI; MOLINA NETO, 2005).

Diante desse cenário ainda desconexo entre teoria e prática, o objetivo do estudo foi analisar a utilização do jogo como ferramenta metodológica para o ensino do esporte na Educação Física escolar. Uma vez identificadas práticas docentes pautadas no jogo, o objetivo específico foi descrever as estratégias metodológicas utilizadas pelos professores no universo de três aulas, destacando as atividades aplicadas para o ensino das modalidades esportivas coletivas.

\section{Metodologia}


Foi conduzido um estudo descritivo, através de abordagem quantitativa e qualitativa. No primeiro momento, todos os professores de Educação Física das redes municipal e estadual que atuavam com turmas de $5^{\circ}$ ao $9^{\circ}$ ano na cidade de Pelotas (RS) foram considerados elegíveis a participar do estudo (cerca de 100 professores).

A pesquisa foi organizada em duas etapas. Na primeira fase, todos os professores elegíveis foram convidados a participar e, a partir dos critérios descritos a seguir, uma amostra de docentes foi selecionada para o estudo principal. Com a colaboração das coordenações da

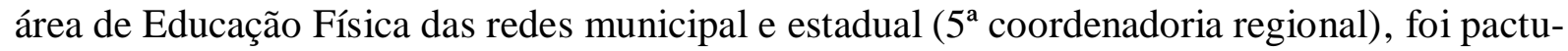
ada uma primeira coleta de dados com os docentes durante a realização de reuniões promovidas pelas respectivas coordenações. Dessa forma, nos meses de junho (rede municipal) e julho (rede estadual) de 2014, durante a realização de um encontro com docentes de cada rede, foi administrado um questionário autoaplicado, contando com as orientações do pesquisador principal. Nessa etapa, um total de 54 docentes participantes dos encontros aceitou responder ao questionário. $\mathrm{O}$ instrumento abordou aspectos demográficos, quanto à formação e à atuação profissional, assim como o trato pedagógico do esporte nas aulas de Educação Física. Para as análises, as informações coletadas com o questionário serviram para a identificação dos professores elegíveis para a etapa seguinte da pesquisa. Duas questões foram centrais para a seleção da amostra de professores cujas aulas seriam observadas:

(a) Opção do método de ensino mais utilizado nas aulas cujo esporte coletivo era o conteúdo, sendo que as opções de resposta eram: método analítico (ensino da técnica isoladamente); método global (pautado pelo jogo formal); método misto (uso das duas abordagens anteriores); outra perspectiva (sendo solicitada a descrição).

(b) Para você, o ensino dos esportes no ensino fundamental deve obedecer a alguma sequencia lógica? As opções de resposta eram: (i) não; (ii) primeiro o ensino da técnica para depois vivenciar experiências táticas; (iii) primeiro vivenciar experiências táticas, para depois focar no ensino da técnica; (iv) outra perspectiva.

Com a análise das respostas da questão "a" foram identificados os docentes que, a partir da opção "outra perspectiva", relataram priorizar o trabalho com metodologia centrada em jogos. Considerando que apenas dois professores definiram sua prática tendo como ênfase a metodologia "centrada em jogos condicionados ou situacionais" (jogos com modificações no formato e/ou regras do jogo formal, com o ensino da técnica e tática de forma simultânea), optou-se por também inserir na segunda fase do estudo aqueles professores que identificaram a importância da vivência de experiências táticas anteriores ao ensino da técnica (questão b). Esta última medida teve a intenção de selecionar docentes que de alguma forma privilegiavam em suas práticas pedagógicas o jogo, além de partilharem da concepção de que a tática pode anteceder o ensino da técnica.

Oito professores se encaixaram nos critérios de inclusão para participar da segunda etapa, sendo que seis estavam disponíveis para participar (dois docentes passaram por licença saúde no período de coleta de dados). Entre os meses de outubro e novembro do mesmo ano foram conduzidas observações de três aulas de Educação Física cujo conteúdo era esporte coletivo entre os professores selecionados. A escolha da turma, série e modalidades foi de responsabilidade do professor. Foi utilizado um instrumento para registro das observações com foco na metodologia de ensino do esporte, testado previamente em estudo-piloto. Para a descrição dos resultados e a preservação das identidades, os professores foram identificados por números ( 1 a 6 ) conforme a ordem de finalização da coleta dos dados.

Um grupo de cinco acadêmicos de Educação Física participou de um treinamento de quatro horas para a realização da coleta de dados. A equipe de pesquisa, acompanhada do pesquisador principal, aplicou o instrumento de registro das observações em quatro aulas de Educação Física em uma escola privada, cujo conteúdo era alguma modalidade coletiva. 
Durante o processo de coleta de dados, os avaliadores pactuaram com os docentes envolvidos os dias e horários das aulas a serem observadas. De posse de um cronômetro e o quadro de definições conceituais, o avaliador registrava o tipo e o tempo de cada atividade desenvolvida na aula. Conforme já utilizado por Borges e Voser (2013), operacionalmente foram assim conceituadas as abordagens de ensino do esporte:

- Centrada na técnica: atividades práticas de forma analítica, através de exercícios técnicos com o objetivo de proporcionar o aprendizado da técnica da modalidade.

- Centrado no jogo formal: prática do próprio jogo formal, com suas regras básicas e sem adaptações significativas. $\mathrm{O}$ ensino da técnica e da tática se dará no próprio jogo.

- Centrado nos jogos condicionados/situacionais: prática de jogos esportivos modificados em seu formato e/ou regras, com o intuito de proporcionar o aprendizado da técnica e da tática simultaneamente.

- Outras atividades: alongamentos, conversa, aquecimento sem bola e recreativo sem bola (sem a intenção de desenvolver a técnica).

A partir do tempo total (minutos) observado nas aulas (denominador), foi calculada a proporção de tempo da utilização de cada abordagem empregada por cada professor.

Ao final da observação de cada aula, foram conduzidas entrevistas com os professores de forma a proporcionar maiores esclarecimentos sobre os objetivos gerais e específicos da aula. Além disso, a entrevista realizada após a terceira observação incluiu perguntas sobre quais mudanças do ponto de vista estrutural o professor entendia serem fundamentais para o aprimoramento do seu trabalho no ensino do esporte em relação à estrutura física, à disponibilidade de materiais e ao número de alunos.

Os dados de observação de aulas coletados foram tratados a partir da estatística descritiva, com cálculo de proporções e médias para os dados categóricos e numéricos, respectivamente. As informações quanto aos objetivos das aulas foram analisadas pelo pesquisador principal segundo a descrição das atividades desenvolvidas. Os dados sobre as condições estruturais para o ensino do esporte foram organizados em grupos de resposta.

O protocolo do estudo foi aprovado pelo Comitê de Ética em Pesquisa da Escola Superior de Educação Física da Universidade Federal de Pelotas (Parecer 868.984). Para a coleta de dados, foi exigida a assinatura do Termo de Consentimento Livre e Esclarecido dos professores em cada etapa do estudo.

\section{Resultados}

A amostra de professores $(\mathrm{N}=6)$ participantes da segunda etapa da pesquisa foi composta por três mulheres e três homens, sendo que dois não tinham curso de pós-graduação, dois eram especialistas, um mestre e uma doutora. Quatro deles participaram nos últimos cinco anos de cursos de formação continuada sobre ensino do esporte. Interessante observar a diversidade de faixa etária, tempo de formado e titulação, como evidencia o Quadro 1.

Quadro 1 - Descrição dos professores de turmas observadas ( $N=6)$.

\begin{tabular}{|l|l|l|l|l|l|}
\hline Professor & Sexo & $\begin{array}{l}\text { Idade } \\
\text { (anos) }\end{array}$ & $\begin{array}{l}\text { Tempo de for- } \\
\text { mado (anos) }\end{array}$ & $\begin{array}{l}\text { Curso de formação } \\
\text { continuada }\end{array}$ & Pós-graduação \\
\hline
\end{tabular}




\begin{tabular}{|l|l|l|l|l|l|}
\hline 01 & Feminino & 42 & 14 & Não & Doutorado \\
\hline 02 & Masculino & 24 & 03 & Sim & Especialização \\
\hline 03 & Feminino & 24 & 04 & Sim & Mestrado \\
\hline 04 & Feminino & 36 & 13 & Não & Não possui \\
\hline 05 & Masculino & 54 & 27 & Sim & Especialização \\
\hline 06 & Masculino & 50 & 30 & Sim & Não possui \\
\hline
\end{tabular}

Fonte: Elaborado pelos autores, 2014.

Ao todo, foram observadas três aulas de cada professor, compreendendo 18 aulas de Educação Física analisadas. As turmas selecionadas pelos professores para serem observadas foram na sua maioria do $6^{\circ}$ ano $(\mathrm{N}=4)$. O tempo total de observação das três aulas variou de 114 a 229 minutos. Um dos professores optou por uma turma que tinha duas aulas consecutivas, explicando o tempo superior às demais. A Figura 1 mostra a proporção média da utilização de cada abordagem metodológica observada. Três professores aplicaram algum tipo de jogo condicionado em pelo menos $40 \%$ do tempo total de aula observado. O método analítico foi observado na prática de cinco docentes, sendo que a proporção máxima de utilização deste método foi de $24 \%$ (professor 5).

Figura 1 - Proporção do tempo de utilização de cada metodologia de ensino do esporte.

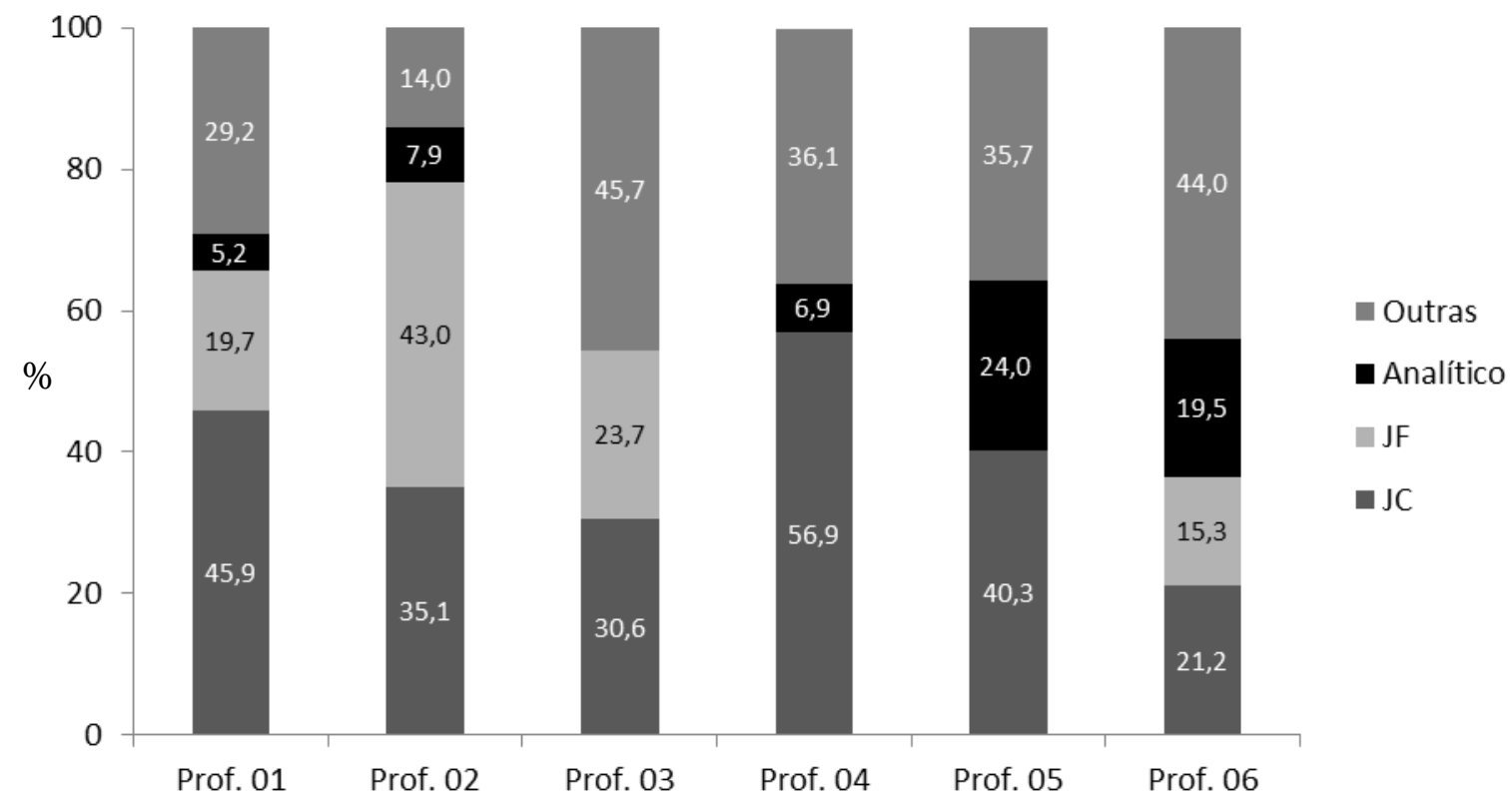

Legenda: JF - Jogo formal / JC - Jogos condicionados.

Fonte: Elaborada pelos autores, 2014.

O Quadro 2 traz a descrição das turmas observadas segundo a série, conteúdos e atividades desenvolvidas nas aulas. As modalidades observadas foram o futsal, handebol, basquetebol e voleibol. Todos os professores utilizaram alguma forma de jogo condicionado, ou seja, com a manutenção dos aspectos centrais da modalidade envolvida, mas com modificações no formato, nas regras ou condições técnicas. O jogo formal foi observado nas aulas de quatro professores, com maior presença do futsal $(\mathrm{N}=3)$. Jogos pré-desportivos foram observados no trabalho de cinco professores, envolvendo atividades com variadas formatações (quanto ao número de jogadores, objetivos, espaço de jogo, entre outros). A utilização da metodologia analítica foi empregada por cinco professores com a perspectiva da aprendizagem de fundamentos técnicos individuais das modalidades de basquetebol e handebol. 
Duas atividades observadas não puderam ser classificadas dentro das categorias previamente estabelecidas. Os professores 1 e 3, ao trabalharem a modalidade de basquetebol com turmas de $5^{\circ}$ e $9^{\circ}$ ano, respectivamente, desenvolveram brincadeiras em formato de corrida de estafetas, que utilizavam da execução de movimentos técnicos da modalidade durante seu desenvolvimento (dribles de diferentes formas, passes etc). Diante disso, considerando que as ações de uma equipe não interferiam diretamente nas ações da(s) equipe(s) adversária(s), esse tipo de atividade não foi classificado como jogo pré-desportivo. Apesar de o conceito inicial da categoria "outras atividades" não incluir a utilização de elementos técnicos da modalidade, optou-se por mantê-las nesse grupo.

Quadro 2 - Descrição das turmas e professores segundo os conteúdos e atividades desenvolvidas nas aulas observadas.

\begin{tabular}{|c|c|c|c|c|}
\hline $\begin{array}{l}\text { Professor/Série/ } \\
\text { Modalidade }\end{array}$ & $\begin{array}{c}\text { Outras ativi- } \\
\text { dades }\end{array}$ & Analítica & $\begin{array}{l}\text { Jogo for- } \\
\text { mal }\end{array}$ & Jogos condicionados \\
\hline $\begin{array}{l}\text { Professor } 1 \\
\text { Série: } 5^{\circ} \text { Ano } \\
\text { Basquetebol }\end{array}$ & $\begin{array}{l}\text { - Conversa } \\
\text { inicial e final } \\
\text { - Verificação } \\
\text { de frequência } \\
\text { cardíaca e } \\
\text { pressão } \\
\text { - Alongamen- } \\
\text { tos } \\
\text { - Brincadeira } \\
\text { em forma de } \\
\text { estafeta en- } \\
\text { volvendo dri- } \\
\text { ble }\end{array}$ & $\begin{array}{l}\text { - Exercício } \\
\text { individual de } \\
\text { drible }\end{array}$ & $\begin{array}{l}\text { - Jogo } \\
\text { formal } \\
\text { separado } \\
\text { por sexo }\end{array}$ & $\begin{array}{l}\text {-Situações de jogo: } \\
\quad-2 \times 2 \\
\quad-3 \times 3+2 \\
\quad-4 \times 4+2 \\
\quad-5 \times 4\end{array}$ \\
\hline $\begin{array}{c}\text { Professor } 2 \\
\text { Série: } 6^{\circ} \text { Ano } \\
\text { Handebol/futsal }\end{array}$ & $\begin{array}{l}\text { - Conversa } \\
\text { inicial e final } \\
\text { - Divisão de } \\
\text { equipes }\end{array}$ & $\begin{array}{l}\text {-Exercício } \\
\text { envolvendo } \\
\text { passe e drible } \\
\text { (handebol) }\end{array}$ & $\begin{array}{l}\text { - Jogo } \\
\text { formal } \\
\text { com ênfa- } \\
\text { se na mar- } \\
\text { cação 6x0 } \\
\text { (handebol) } \\
\text { - Jogo } \\
\text { formal } \\
\text { (futsal) }\end{array}$ & $\begin{array}{l}\text { - Grande jogo com ênfa- } \\
\text { se no desenvolvimento } \\
\text { de noções individuais e } \\
\text { coletivas de defesa (han- } \\
\text { debol) } \\
\text { - Jogo com modificações } \\
\text { de regra (sem progres- } \\
\text { sões) e alvo modificado } \\
\text { (handebol) }\end{array}$ \\
\hline $\begin{array}{c}\text { Professor } 3 \\
\text { Série: } 9^{\circ} \text { Ano } \\
\text { Basquetebol/futsal/ } \\
\text { voleibol }\end{array}$ & $\begin{array}{l}\text { - Conversa } \\
\text { inicial e final } \\
\text { - Reflexões } \\
\text { sobre o jogo } \\
\text { - Alongamen- } \\
\text { tos } \\
\text { - Caminhada } \\
\text { - Brincadeira } \\
\text { em forma de } \\
\text { estafeta en- } \\
\text { volvendo di- }\end{array}$ & & $\begin{array}{l}-\quad \text { Jogo } \\
\text { formal } \\
\text { (futsal) } \\
-\quad \text { Jogo } \\
\text { formal } \\
\text { (voleibol) }\end{array}$ & $\begin{array}{l}\text { - Jogo com modificações } \\
\text { de regra (não era permi- } \\
\text { tido driblar ou tirar a } \\
\text { bola da mão do adversá- } \\
\text { rio); todos os jogadores } \\
\text { deveriam receber a bola } \\
\text { antes da finalização; pas- } \\
\text { ses interceptados eram } \\
\text { pontuados (basquetebol) } \\
\text { - Jogo envolvendo pas- } \\
\text { ses (com variações), cuja }\end{array}$ \\
\hline
\end{tabular}




\begin{tabular}{|c|c|c|c|c|}
\hline & \begin{tabular}{|l|} 
ferentes fun- \\
damentos \\
técnicos (bas- \\
quetebol) \\
\end{tabular} & & & $\begin{array}{l}\text { meta era transportar a } \\
\text { bola ao objetivo (aluno) } \\
\text { na quadra adversária } \\
\text { (basquetebol) }\end{array}$ \\
\hline $\begin{array}{l}\text { Professor } 4 \\
\text { Série: } 6^{\circ} \text { Ano } \\
\text { Handebol }\end{array}$ & $\begin{array}{l}\text { - Conversa } \\
\text { inicial } \\
\text { - Divisão de } \\
\text { equipes } \\
\text { - Montagem } \\
\text { da quadra } \\
\text { - Explicações } \\
\text { sobre o jogo }\end{array}$ & $\begin{array}{l}\text { - Exercícios } \\
\text { de arremesso } \\
\text { individual }\end{array}$ & & $\begin{array}{l}\text { - Jogo pré-desportivo } \\
\text { (jogo dos } 10 \text { passes) com } \\
\text { alternância por sexo na } \\
\text { realização dos passes } \\
\text { - Jogo com modifica- } \\
\text { ções de regra (número } \\
\text { mínimo de cinco passes, } \\
\text { alternância por sexo na } \\
\text { realização dos passes, } \\
\text { impedimento do passe de } \\
\text { retorno, com permissão } \\
\text { para arremessar sem } \\
\text { marcação com progres- } \\
\text { são de três passadas) }\end{array}$ \\
\hline $\begin{array}{l}\text { Professor } 5 \\
\text { Série: } 6^{\circ} \text { ano } \\
\text { Handebol }\end{array}$ & $\begin{array}{l}\text {-Conversa } \\
\text { inicial } \\
\text { - Divisão de } \\
\text { equipes } \\
\text {-Explicações } \\
\text { sobre o jogo } \\
\text { - Aula teórica } \\
\text { (sistemas táti- } \\
\text { cos) }\end{array}$ & $\begin{array}{l}\text { - Exercícios } \\
\text { de arremesso } \\
\text { individual } \\
\text { com progres- } \\
\text { são (3 passos) } \\
\text { e movimento } \\
\text { de arremesso } \\
\text { (sem bola e } \\
\text { posteriormente } \\
\text { com bola) }\end{array}$ & & $\begin{array}{c}- \text { Situações de jogo: } \\
-2 \times 1+1 \\
-1 \times 1+1 \\
-3 \times 3\end{array}$ \\
\hline $\begin{array}{c}\text { Professor } 6 \\
\text { Série: } 6^{\circ} \text { Ano } \\
\text { Futsal/Basquetebol }\end{array}$ & $\begin{array}{l}\text { - Conversa } \\
\text { inicial } \\
\text { - Caminhada } \\
\text { - Corridas } \\
\text { - Circuito } \\
\text { psicomotor } \\
\text { - Divisão de } \\
\text { equipes } \\
\text { - Explicações } \\
\text { sobre o jogo }\end{array}$ & $\begin{array}{l}\text { - Exercícios } \\
\text { individuais de } \\
\text { drible (bas- } \\
\text { quetebol) }\end{array}$ & $\begin{array}{l}- \text { Jogo } \\
\text { formal } \\
\text { (futsal) }\end{array}$ & $\begin{array}{l}\text { - Jogo pré-desportivo } \\
\text { com grande grupo, cujo } \\
\text { objetivo era transportar a } \\
\text { bola de basquetebol atra- } \\
\text { vés de passes até o alvo } \\
\text { (um aluno em pé numa } \\
\text { cadeira) (basquetebol) }\end{array}$ \\
\hline
\end{tabular}

Fonte: Elaborado pelos autores, 2014

A análise comparativa entre os objetivos de cada aula citados pelos professores e as atividades observadas demonstrou coerência entre o planejado e o executado. Os objetivos foram centrados na perspectiva da aprendizagem dos aspectos técnicos e táticos das modalidades envolvidas. Ao serem questionados sobre possíveis alterações nas condições de trabalho para o alcance dos objetivos da disciplina de Educação Física, os professores foram unânimes quanto à relevância na qualificação dos espaços físicos. Os aspectos fundamentais citados foram: dimensões ampliadas, piso adequado e cobertura das quadras. O professor 6 destacou a necessidade da presença das tabelas de basquetebol para o desenvolvimento desse con- 
teúdo em sua escola (salienta-se aqui o fato de o professor ter trabalhado esse conteúdo mesmo sem as tabelas).

Em relação aos materiais didáticos, apenas um professor manifestou satisfação com os recursos que sua escola disponibilizava. Entre os demais docentes, aspectos como maior quantidade, diversidade e qualidade das bolas esportivas foram mencionados, assim como a disponibilidade de bolas adequadas à idade. Quanto ao número de alunos nas turmas, metade dos docentes entendeu que em suas escolas não há problemas nesse sentido. Por outro lado, dois professores ( 1 e 3 ) destacaram que o trabalho poderia atingir maior qualidade com a diminuição do número de alunos nas turmas, enquanto o professor 5 demonstrou preocupação com a necessidade de aumentar a quantidade de discentes.

\section{Discussão}

Os resultados da pesquisa evidenciaram a viabilidade da utilização de metodologias de ensino que valorizam o aprendizado do esporte através do jogo no ambiente da aula de Educação Física. No universo das 18 aulas observadas, foi possível identificar que metade dos professores privilegiou sua intervenção em atividades pautadas pelo jogo, se comparado a outras metodologias.

A considerar os objetivos elencados para o trato do esporte na faixa etária em questão, foi possível identificar coerência com o proposto por autores da área. A faixa etária envolvida na pesquisa, com alunos de $5^{\circ}$ ao $9^{\circ}$ ano, corresponde às Fases Universal (6 a 12 anos) e de Orientação (12 a 14 anos), de acordo com Greco e Benda (1998). Os autores sugerem que, a partir dos 8 anos, os alunos podem se envolver com "jogos coletivos, através de pequenos jogos (reduzidos), jogos de iniciação, grandes jogos e em alguns casos, jogos pré-desportivos" (GRECO; BENDA, 1998, p. 68).

As observações das aulas revelaram a utilização de diferentes estruturas de jogo pautadas pela lógica das modalidades esportivas em questão. Por exemplo, ao lidar com o basquetebol e handebol, jogos pré-desportivos foram observados na forma do tradicional "jogo dos passes" ou modificação do alvo do jogo (cesta adaptada no basquete).

Outra estratégia para operacionalização dos jogos observada foi a utilização de um menor número de jogadores. As Estruturas Funcionais (GRECO, 2001) sugerem a organização das ações de ataque contra defesa de forma semelhante ao jogo formal, mas com nível de complexidade menor, obtido pela redução do número de participantes (atacantes e/ou defensores), diminuição do espaço de jogo, mudanças de regras, entre outros. Tais medidas objetivam facilitar o acesso ao jogo pelo iniciante, sem deixar de fomentar o desenvolvimento dos aspectos importantes da modalidade, além de incorporar tarefas táticas (GRECO, 2001). Além disso, as Estruturas Funcionais permitem também a utilização de "curingas", ou seja, jogadores com funções exclusivamente ofensivas e que atuam com o intuito de apoiar os atacantes (GRECO, 1998). Ao tratar pedagogicamente do basquetebol (professor 1) e handebol (professor 5), foram observadas atividades organizadas em estruturas como $1 \times 1+1,2 \times 1+1,2 \times 2+2$, $3 \times 3+2$, entre outras.

O jogo em sua estrutura fundamental (número de jogadores, bola, espaço e alvo), mas com alterações de regras, também se fez presente entre as estratégias de ensino observadas. Ao trabalhar o basquetebol e o handebol dentro do jogo formal, modificações intencionais foram implementadas, como a proibição do drible, a exigência de que todos atacantes deveriam receber a bola antes da finalização, o número mínimo de passes, a restrição aos passes de retorno, a inexistência das passadas (progressão no handebol), entre outras. Tais modificações contribuíram para que, dentro do contexto do jogo, as técnicas (como os diferentes tipos de passe no basquetebol ou arremesso no handebol) surgissem em função da tática, de forma orientada e provocada (GARGANTA, 1995; PAES; MONTAGNER; FERREIRA, 2009). 
Em que pese uma recorrente preocupação com a ênfase dada aos métodos pautados pelo princípio analítico-sintético no ensino do esporte, ou seja, a utilização demasiada de exercícios para o aprendizado ou o aperfeiçoamento da técnica em contexto desvinculado do jogo (GRECO, 1998; GALATTI, 2014), se faz importante considerar que tal metodologia apresenta relevância e aplicabilidade a partir de sua especificidade. Em nosso estudo, cinco dos seis docentes que foram observados recorreram em alguma das aulas aos exercícios técnicos isolados do jogo. Considerando os objetivos elencados pelos professores, os exercícios foram aplicados com o intuito de proporcionar a vivência (aprendizado) ou o refino (aperfeiçoamento) dos gestos técnicos em questão, como o arremesso no handebol e o drible no basquetebol.

Conforme diversos autores (GRECO; BENDA, 1998; GARGANTA, 1995; COSTA; NASCIMENTO, 2004), a utilização do jogo com modificações que atendam a objetivos predefinidos e que esteja ao alcance das possibilidades do aluno proporciona diversas vantagens, como: a aprendizagem ocorre de maneira gradativa; o próprio aluno participa do processo de tomada de decisão, o que o torna "agente ativo no seu processo de aprendizagem"; torna-se viável trabalhar aspectos técnicos e táticos simultaneamente e, como consequência, o aprendizado das técnicas surge em função da tática (jogo), de forma orientada e provocada.

A contribuição de uma intervenção que privilegia o ensino através do jogo em comparação a outras abordagens vem sendo mostrado na literatura. Por exemplo, Pérez Morales e Greco (2007) avaliaram o comportamento tático de alunos de três grupos distintos de escolinhas de basquetebol, com meninos de 10 a 12 anos de idade. Entre as conclusões do estudo, destaca-se o fato de que o grupo cujo processo de ensino-aprendizagem-treinamento teve ênfase numa metodologia situacional-global (jogos modificados e jogo formal) apresentou resultados superiores em termos de resolução de problemas de ordem tática, se comparado aos grupos que apresentaram maior contribuição de métodos centrados na técnica (PÉREZ MORALES; GRECO, 2007).

Diferente do trabalho realizado no ambiente de escolinhas, projetos sociais e clubes, espaço em que a participação discente é voluntária, o contexto da aula de Educação Física tende a ser desafiador, por suas características particulares. Assim como já apontado em outros estudos (SANTINI; MOLINA NETO, 2005; DAMAZIO; SILVA, 2008), há uma preocupação quanto às limitações da escola em termos de estrutura física e material para o melhor desenvolvimento dos conteúdos da disciplina de Educação Física, incluindo o esporte. Além disso, a heterogeneidade de "motivações" e habilidades motoras representam importantes aspectos a serem tratados no planejamento e na organização das aulas. Possivelmente esses fatores, somados a outros como insatisfação com salários e carreira, têm contribuído para que seja possível verificar a presença marcante do "jogo livre" como recurso metodológico (HINO; REIS; ANEZ, 2007; FORTES et al, 2012).

O jogo livre, também chamado de "rola bola" (DARIDO, 2008), tem sido associado a uma prática docente descomprometida e pouco organizada. Além disso, preocupa o fato de que o jogo pelo jogo, ou seja, aquele em que os alunos desfrutam de autonomia na organização da atividade e com a carência de objetivos e participação docente, tende a ser agradável apenas aos alunos que já sabem jogar. Dessa forma, aqueles que mais precisariam da intervenção pedagógica ficam prejudicados, às vezes totalmente excluídos, dentro de um espaço que deveria proporcionar o acesso e aprendizagem do esporte a todos.

Uma limitação do estudo precisa ser considerada. A dificuldade de conceituar ou identificar determinada perspectiva pedagógica por meio do questionário pode ter representado a não detecção de outros professores para a segunda etapa da pesquisa.

\section{Conclusões}


A análise in loco de práticas docentes revelou que o ambiente da escola pública, apesar das limitações de espaço e material, se mostrou viável para um trato pedagógico na iniciação às modalidades esportivas de forma mais abrangente, tratando a técnica e a tática de maneira planejada e intencional dentro do contexto de jogos condicionados.

Sobre o cenário geral acerca das práticas pedagógicas de ensino do esporte na rede pública na cidade de Pelotas, pelo menos duas perspectivas podem guiar as conclusões do estudo. Inicialmente, a partir de um olhar pouco animador, o pequeno número de sujeitos selecionados para a etapa principal do estudo pode representar o quão distante o discurso da literatura científica está dos ambientes de intervenção profissional. Por outro lado, numa visão mais otimista, o exemplo apresentado pelo trabalho dos docentes investigados sugere que mudanças significativas nas metodologias de ensino do esporte são possíveis, incluindo o espaço da aula de Educação Física na escola. Assim, esperamos que o conhecimento aplicado, como as abordagens metodológicas aqui apresentadas, possa contribuir para que outros professores tenham a oportunidade de refletir e dar outros significados às suas próprias práticas.

Por fim, se faz importante reconhecer que modificações no campo de atuação profissional relacionado a um ensino do esporte mais direcionado às necessidades dos alunos passam também por esforços simultâneos entre cursos de graduação em Educação Física e Esportes, assim como de ações de formação continuada que envolvam professores que estão atuando na escola.

\title{
TEACHING SPORTS THROUGH GAME PRACTICE: ANALYSIS, POSSIBILITIES AND CHALLENGES IN PHYSICAL EDUCATION
}

\begin{abstract}
The aim of this study was to analyze the use of the game as a methodological tool for the teaching of sports in Physical Education. Teachers linked to the state and municipal education working in the city of Pelotas - Rio Grande do Sul (Brazil) (N=54) answered a questionnaire addressing the preferred methodology for the teaching of collective sports. The analysis of this article was restricted to observation of physical education classes of six teachers who characterized their approach based on the game practice. The results showed the feasibility of using different structures of games in the initiation of the collective modalities involved in the school environment, despite the structural constraints which were identified, such as space and availability of materials.
\end{abstract}

Keywords: Physical Education and Training. Sports. Methodology.

\section{LA ENSEÑANZA DEL DEPORTE POR MEDIO DEL JUEGO: ANÁLISIS, POSIBI- LIDADES Y RETOS EN LA EDUCACIÓN FÍSICA ESCOLAR}

\section{Resumen}

El objetivo del estudio fue analizar la utilización del juego como una herramienta metodológica para la enseñanza del deporte en la Educación Física escolar. Profesores vinculados a las redes municipal y estatal, que actúan en la ciudad de Pelotas-RS $(\mathrm{N}=54)$, respondieron un cuestionario que se centró en la metodología preferencial para la enseñanza de las modalidades deportivas colectivas. A partir de eso, se identificaron seis maestros, cuya intervención profesional tenía características de enseñanza dirigida por el juego. Las clases de esos maestros de educación física fueron observadas y analizadas. Los resultados mostraron la factibilidad de la utilización de distintas estructuras de juego en la iniciación a las modalidades colec- 
tivas que envuelven el ambiente escolar, a pesar de las restricciones estructurales identificadas, como espacio físico y disponibilidad de materiales.

Palabras clave: Educación Física. Deporte. Metodología.

\section{Referências}

BAYER, C. O ensino dos desportos colectivos. Lisboa: Dinalivro, 1994.

BETTI, I. C. R. Esporte na escola: Mas é só isso professor? Revista Motriz, Rio Claro, v. 1, n. 1, p. 25-31, jun.1999.

BORGES, R.R.K.; VOSER. R.C., Análise dos métodos de ensino em escolas de futsal de Porto Alegre. Revista Digital, Buenos Aires, ano 18, n.180, maio. 2013. Disponível em:<http://www.efdeportes.com/efd85/futsal.htm>. Acesso em: 15 jun. 2014.

BUNKER, D.; THORPE, R.A model for the teaching of games in the secondary school. Bulletin of Physical Education, v. 10, p. 9-16, 1982.

COSTA, L. C. A.; NASCIMENTO, J. V. O ensino da técnica e da tática: novas abordagens metodológicas. Revista da Educação Física. Maringá. v. 15, n. 2, p. 49-56, 2004.

CÔTÉ, J.; BAKER, J.; ABERNETHY, B. Practice and play in the development of sport expertise. In: EKLUND, R.; TENENBAUM, G. (Ed.). Handbook of Sport Psychology, Hoboken, 2007.

COUTINHO, N. F.; SILVA, S. A. P.S. Conhecimento e aplicação de métodos de ensino para os jogos esportivos coletivos na formação profissional em Educação Física. Movimento, v. 15, n. 1, p. 117-144, 2009.

DAMAZIO, M. S.; SILVA, M.F.P. O ensino da Educação Física e o espaço físico em questão. Revista Pensar a Prática, Goiânia, v.11, n. 2, p. 197-207, maio/ago, 2008.

DARIDO, S.C. Educação Física na escola: questões e reflexões. Rio de Janeiro: Guanabara Koogan, 2008.

DIETRICH, K.; DÜRRWÄCHTER, G.; SCHALLER, H. Os grandes jogos: metodologia e prática. Rio de Janeiro: Ao Livro Técnico, 1984.

FORTES, M.O. et al. A Educação Física escolar na cidade de Pelotas-RS: contexto das aulas e conteúdos. Revista de Educação Física, Maringá, v. 23, n. 1, p. 69-78, 2012.

GALATTI, L. R. et al. Pedagogia do esporte: a diversidade na iniciação em basquetebol. In: RAMOS, V.; SAAD, M. A. MILISTETD, M. (Org.) Jogos desportivos coletivos: investigação e prática pedagógica. Florianópolis: UDESC, 2013. p. 81-104.

Pedagogia do esporte: tensão na ciência e o ensino dos jogos esportivos coletivos.

Revista da Educação Física, Maringá, v. 25, n. 1, p. 153-162, 2014. 
GARGANTA, J. Para uma teoria dos jogos desportivos coletivos. In: GRAÇA, A.; OLIVEIRA, J. (Org.) O ensino dos jogos desportivos. Porto: Faculdade de Ciências do Desporto e de Educação Física, Universidade do Porto, 1995. p.11-25.

O ensino dos jogos desportivos coletivos. Perspectivas e tendências. Revista Movimento, Porto Alegre, v. 4, n.8, p. 19-27, 1998.

GRAÇA, A.; OLIVEIRA, J. O ensino dos jogos desportivos. Porto: Faculdade de Ciências do Desporto e de Educação Física, Universidade do Porto, 1995.

GRECO, P. J.; BENDA, R. N. (Org.) Iniciação esportiva universal: da aprendizagem motora ao treinamento técnico. Belo Horizonte: UFMG, v. 1, 1998.

GRECO, P. J. Iniciação esportiva universal 2: metodologia da iniciação esportiva na escola e no clube. Belo Horizonte: UFMG, 1998.

Métodos de ensino-aprendizagem-treinamento nos jogos esportivos coletivos. In: GARCIA, E.S.; LEMOS, K.L.M. (Org.). Temas Atuais VI - Educação Física e Esportes. Belo Horizonte: Health, 2001, p. 48-72.

GRECO, P.J; SILVA, S. A.; SANTOS, L. R. Organização e planejamento pedagógico do esporte no Programa Segundo Tempo. In: OLIVEIRA, A.A.B.; PERIM, G. L. (Org.) Fundamentos pedagógicos do Programa Segundo Tempo: da reflexão à prática. Maringá: EDUEM, 2009. p.165-208.

GRIFFIN, L.; L. et al. Teaching sport concepts and skill: a tactical games approach. Champing. Human Kinetics, 1997

HINO, A. A. F.; REIS, R. S.; ANEZ, C. R. R. Observação dos níveis de atividade física, contexto das aulas e comportamento do professor em aulas de educação física do ensino médio da rede pública. Revista Brasileira de Atividade Física \& Saúde, Londrina, v. 12, n. 3, p. 2130, set./dez. 2007.

PAES, R. R; MONTAGNER, P.C.; FERREIRA, H.B. Pedagogia do esporte: iniciação e treinamento em basquetebol. Rio de Janeiro: Guanabara Koogan, 2009.

PÉREZ MORALES, J.C.; GRECO, P.J. A influência de diferentes metodologias de ensinoaprendizagem-treinamento no basquetebol sobre o nível de conhecimento tático processual. Revista Brasileira de Educação Física e Esporte, São Paulo, v.21, n.4, p.291-99, out./dez. 2007.

RAMOS, V.; GRAÇA, A.B.S.; NASCIMENTO, J.V. A representação do ensino do basquetebol em contexto escolar: estudos de caso na formação inicial em Educação Física. Revista Brasileira de Educação Física e Esporte, São Paulo, v.20, n.1, p.37-49, jan./mar. 2006.

REVERDITO, R. S.; SCAGLIA, A. J. Pedagogia do esporte: jogos coletivos de invasão. São Paulo: Phorte, 2009.

SANTINI, J.; MOLINA NETO, V. A síndrome do esgotamento profissional em professores de Educação Física: um estudo na rede municipal de ensino de Porto Alegre. Revista Brasileira de Educação Física e Esporte, São Paulo, v.19, n.3, p.209-22, jul./set. 2005. 
SCAGLIA, A.; REVERDITO, R.; GALATTI, L. Ambiente de jogo e ambiente de aprendizagem no processo de ensino dos jogos esportivos coletivos: desafios no ensino e na aprendizagem dos jogos esportivos coletivos. In: NASCIMENTO, J.; RAMOS, V.; TAVARES, F. (Org.). Jogos desportivos: formação e investigação. Florianópolis: Editora Tribo da Ilha, 2013.

SIEDENTOP, D. Sport education: a retrospective. Journal of Teaching in Physical Education, v. 21, p. 409-418, 2002.

WITTIZORECKI, E.S.; MOLINA NETO, V. O trabalho docente dos professores de Educação Física na rede municipal de Porto Alegre. Movimento, v. 11, n. 1, p. 47-70, 2005.

Recebido em: 22/04/2016

Revisado em: 11/07/2016

Aprovado em: 01/09/2016

Endereço para correspondência:

mrazevedojr@gmail.com

Mario Renato Azevedo

Universidade Federal de Pelotas,

Escola Superior de Educação Física

Rua Luiz de Camões, 166

Tablada

96055630 - Pelotas, RS - Brasil 